\title{
Co-teaching Effectiveness: Students' Achievement in Mathematical Proficiencies and Content Strands
}

\author{
Muhammad Zafar Iqbal * \\ Jahan Ara Shams **
}

\begin{abstract}
In Pakistan Mathematics is being taught by single teacher. In contrast coteaching has shown its positive effects on students' academic achievement in Mathematics. Keeping in view the importance of co-teaching, this study was aimed at examining the co-teaching effectiveness to enhance students' scores in mathematics. An experimental research design, Solomon Four Group was applied in this study to conduct an experiment. A school in the public sector was selected on convenient basis with due permission of headmaster. There were 118 students studying in that school at $8^{\text {th }}$ grade situated in Sargodha district. A teaching module of mathematics was developed on two content strands of $8^{\text {th }}$ grade mathematics i.e. algebra $\&$ geometry. The duration for one lesson was one hour. There were 20 lessons in the module and were validated by two mathematics experts. Students' achievement was measured by using an achievement test of mathematics. Pakistan National Educational Assessment System had developed and validated the items. Data were analyzed by applying Mean, Standard deviation, and independent sample t-test. Co-teaching was found to be more effective than single teacher's teaching in enhancing students' achievement score in algebra and geometry with mathematical proficiencies. It was recommended that a topic on co-teaching should be included in courses preparing teachers of Mathematics.
\end{abstract}

Keywords: co-teaching, students' achievement, mathematics, mathematical proficiencies

\footnotetext{
* Lecturer, Allama Iqbal Open University Islamabad, Email: mzafar.iqbal@aiou.edu.pk

** Assistant Professor, Punjab Higher Education Department Lahore,

Email: jahanarashams@gmail.com
} 


\section{Introduction}

Mathematics is the kind of subject which provides foundations for the study of other science subjects (e.g. Physics, Chemistry). It is also helpful in studying business subjects like Economics, Statistics, and Accounting. It is a unique subject with specific language and signs of mathematics. Many Mathematics students face problems in learning mathematical concepts because of its abstraction.

Researchers like Russell (2006) have explored that mathematics students faced learning problems due to single teachers' teaching as compared with co-teaching. Mcduffe, Scruggs, and Mastropieri (2007) found that teaching of Mathematics in collaborative settings produced better results than single teachers' teaching. Single teachers' poor handwriting, weak focus on students' questions and some time no reply due to busy on using black board, same teaching style, fast writing speed, weak mathematical concepts, poor classroom management of large number of students creates problems for students to learn Mathematics effectively. Teachers overcome their feeling of isolation when teaching in collaborative settings (Robinson \& Schaible, 1995).

Mostly, one way teaching of Mathematics with deductive method is being used by single teachers in the Pakistani classroom settings at grade 8 . Students usually sit in the class separately and do not collaborate with each other. They do not work in groups or in collaboration. Their task is to just to note down the answers of what teacher writes on the blackboard. Teachers do not focus on the understanding of concepts rather just solving mathematics exercises given in the text books. They dictate Mathematical formulae first and students are supposed to memorize those formulae to solve Mathematical exercises. They are hesitant to discuss concepts with colleagues. Thus students' low achievements in Mathematics persist.

So, co-teaching or collaborative settings teaching with many benefits can be better alternative to traditional deductive method to teach Mathematics at $8^{\text {th }}$ grade level in Pakistan. Researchers conducted their studies on student-student interaction rather teacher-teacher interaction in Pakistan for example, Iqbal 2004, Khan 2008, Ahmad 2014, and Akhtar, Perveen, Kiran, Rashid, \& Satti 2012. Although some research work has been done on the effectiveness of co-teaching worldwide on different grades, but in Pakistan no research study was found that investigate the effectiveness of co-teaching on improving scores of Mathematics students'. 
Thus, examining Mathematics teaching with different collaborative settings in relation to improve students' scores is vital.

\section{Literature Review}

\section{What is Co-teaching?}

Collaborative settings are the main characteristics of this kind of teaching. Teachers with equal qualification and experience can involve in teaching together with varies role but with common goals (Sperling, 1994). The basis of collaboration lies in the philosophy of constructivism. John Dewey was the founder of this approach in which co-equal individuals construct new ideas. Parrott (n. d.), described collaborative settings for teaching in five elements shown in figure 1.

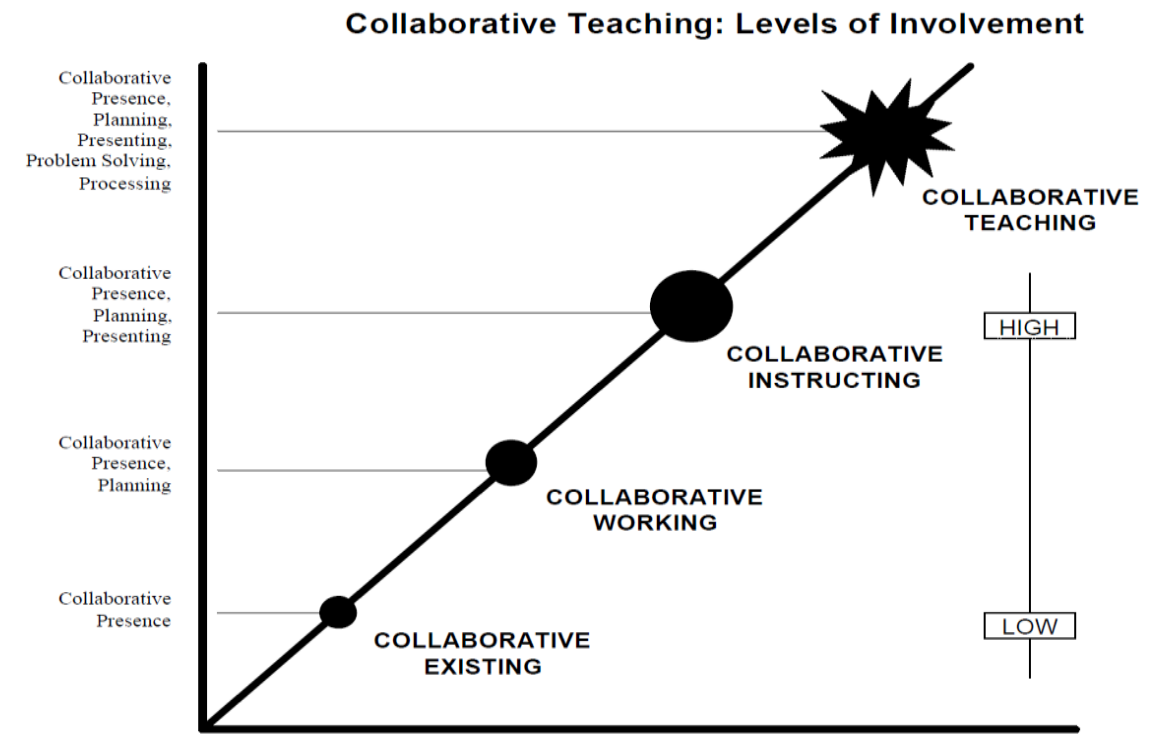

Figure 1: Collaborative settings levels

\section{Researches on Teachers' Collaboration}

Many research studies conducted internationally for example, Jang (2006) used quasi experimental design to examine team teaching's effect on the achievement scores of grade 8 Mathematics students. In the study two teachers collaboratively teach mathematics for six week period. Significant 
difference was found students' achievement scores taught through team teaching and traditional teaching in mathematics. He suggested using true experimental design. Similarly, Parker (2010) conducted an experiment on $10^{\text {th }}$ grade mathematics students to investigate co-teaching effectiveness to increase students' scores. Students' achievement was measured by achievement test. Significant difference was found in students' scores taught through co-teaching and without co-teaching. Further, Goddard, Goddard, \& Moran (2007) explored the relationship between teacher-teacher interaction and mathematics students' achievement. The data were collected from US schools at elementary level. It was revealed that high scores were obtained by the students where collaborative teaching was used in schools. Moreover, Witcher and Feng (2010) compared mathematics co-teaching with single teachers' teaching effect to enhance $5^{\text {th }}$ grade students' scores. Two $5^{\text {th }}$ grade classes were participated in study. They applied inferential statistics such as independent samples t-tests to compare students' scores. It was concluded that that co-teaching was better alternative to single teachers' teaching. Last but not the least, Almon and Feng (2012) conducted study with the same purpose. It was conducted on $4^{\text {th }}$ grade students. A test was used to measure students' achievement in the topics such as numbers, mathematical operations i.e. multiplication \& division. Mixed results were found. For example in the mathematical operation of multiplication, students taught through solo teaching showed better scores than co-teaching; While the order of better teaching was reversed in numbers.

\section{Models of Co-teaching}

There are six models of teachers' collaboration. In the first co-teaching model i.e. one teaches one observes, one teacher teaches the students and in the same time the other teacher observes the students in the same class. The next model is one teaches and one assists. In this setting for collaboration, one teacher gives instruction to the students and the other teacher assist the students in learning mathematics by reaching them in the class at the same time. The second teacher may assist the first teacher in delivering lesson by helping him in managing charts and activities (Friend \& Cook, 2000). The best advantage of this model is that one teacher will remain free to help students and teacher (Wilson \& Martin, 1998). The $3^{\text {rd }}$ model named is station teaching. Both teachers are involved in imparting instructions in this kind of collaborative setting. Students are supposed to move from one station to other station for learning. The students moved in pre-planned stations while teachers provide pre-planned instructions. Parallel teaching, $4^{\text {th }}$ model, process starts with the division of a class into two equal groups. Each group 
of students receives instructions independently (Friend \& Cook, 2000). It is appropriate to use this model when there is need to meet diversified students (Cuellar, 2011). Alternative teaching includes two groups in the class. One is larger group than the other. The teacher usually takes remedial classes with small group. The teacher teaches different topic to the small group. Lastly team teaching involves both teachers simultaneously working together to teach students in the classroom. In team teaching both co-teachers share teaching responsibilities and are equally involved in leading instructional activities.

The focus of study objectives were to:

i. Design $8^{\text {th }}$ grade Mathematics teaching module by applying coteaching settings.

ii. Compare the effectiveness of co-teaching and traditional teaching in enhancing students' scores on Mathematical proficiencies test items in algebra and geometry.

\section{Hypotheses of the Study}

The hypotheses were as follows:

$\mathrm{H}_{01}$ : Mean scores of $8^{\text {th }}$ grade mathematics students in control and experimental groups do not differ significantly on understanding items in algebra.

$\mathrm{H}_{02}$ : Mean scores of $8^{\text {th }}$ grade mathematics students in control and experimental groups do not differ significantly on procedural knowledge items in algebra.

$\mathrm{H}_{03}$ : Mean scores of $8^{\text {th }}$ grade mathematics students in control and experimental groups do not differ significantly on problem solving items in algebra.

$\mathrm{H}_{04}$ : Mean scores of $8^{\text {th }}$ grade mathematics students in control and experimental groups do not differ significantly on understanding items in geometry.

$\mathrm{H}_{05}$ : Mean scores of $8^{\text {th }}$ grade mathematics students in control and experimental groups do not differ significantly on procedural knowledge items in geometry. 
$\mathrm{H}_{06}$ : Mean scores of $8^{\text {th }}$ grade mathematics students in control and experimental groups do not differ significantly on problem solving items in geometry.

\section{Methodology}

\section{Design of the Study}

An experimental research study was designed to investigate coteaching effectiveness in enhancing $8^{\text {th }}$ grade students' scores in mathematics. An achievement test of mathematics was used to measure students' mathematical proficiencies. True experimental design i.e. Solomon Four Group was used in this study. According to Cresswell (2002) all the groups receive post-tests. The subjects were assigned randomly to all the groups. Fraenkel and Wallen (2006) stated that it is essential in true experimental design that subjects must be selected and assigned to groups randomly. According to Best and Kahn (2008) the internal validity threats can be best control by this design. The experiment was conducted for 37 days and it was appropriate when compared with given time allocation on the Punjab schools website. One lesson was allocated 60 minutes in this research study. It was happened by combining two consecutive class periods i.e. 30 minutes each.

\section{Sampling}

One school from public sector was selected on convenient basis from Sargodha. Prior permission from the head of the school was taken. Students' studying in $8^{\text {th }}$ grade i.e. 118 were included in this study. Further they randomly assigned to four groups. Out of them two were experimental and two were control groups.

\section{Participants}

Two teachers who were teaching mathematics at $8^{\text {th }}$ grade participated in the experiment voluntarily. They were qualified as M.Sc. mathematics with B.Ed. the first researcher with same qualification also participated as co-teacher in this study. 


\section{Collaborative Settings}

The collaborative settings used in this research were team teaching, one teach-one assist, and alternative teaching. The detail of co-teaching settings and traditional classroom setting were given in the figure $2 \& 3$.
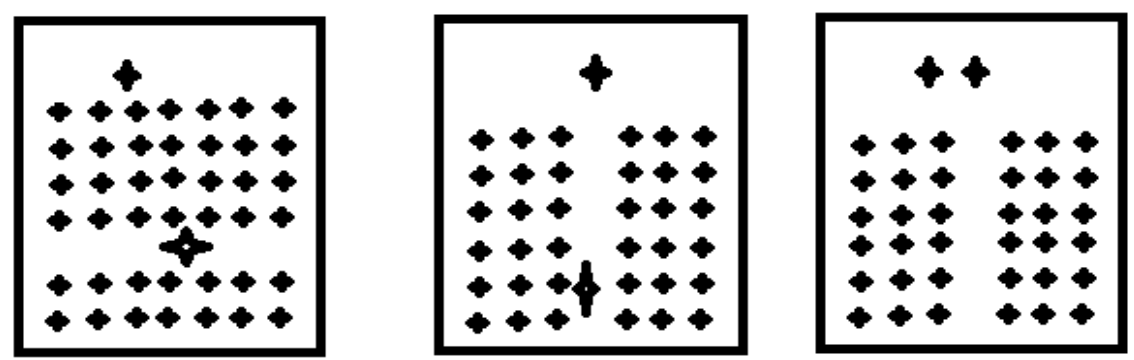

Figure 2: Collaborative Teaching setting i.e. alternative teaching, one teach-one assist, and team teaching

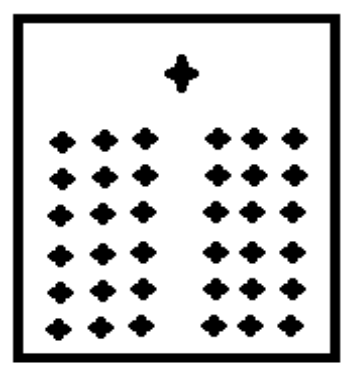

Figure 3: Traditional teaching i.e. single teacher teaching

\section{Training of Volunteer Mathematics Teachers}

Two days training with two mathematic teachers was held before starting the experiment. The time for the sessions were two hours each day. On day1 researcher introduced himself to the sampled teachers. He told to the volunteer teachers about the objectives and syllabus to be covered. He shared with them the schedule of classes that includes time and topics. Both teachers were requested to be regular and punctual. On day 2, first researcher separately explained the co-teacher about coteaching settings that how will the co-teaching take place? What measures should be taken before applying teaching in collaborative settings? 


\section{Co-teachers Collaboration}

In this research study both the teachers met regularly on daily basis for one hour for planning, developing lessons, decisions about collaborative settings, time management of teachers, and students. Matters relating to the availability of classrooms, suitability of time table, related facilities, and schedule of extra classes were discussed informally during school working. Change in classes schedule was made earlier.

\section{Research Instrument}

An achievement test of mathematics was used in this study as a measuring tool. It was MCQs type based on four options. The items had been developed by the NEAS, a National institute for educational assessment. Mathematics content had divided in to five strands such as arithmetic, algebra, geometry (measurement and construction) and probability. Their weightages in the national mathematics curriculum in 2000 were in $43 \%, 32 \%, 20 \%$, and $5 \%$ respectively. According to textbook of mathematics at $8^{\text {th }}$ grade these strands were having related outcomes $12,6,5$, and 3 respectively. This research included only two strands i.e. algebra and measurement geometry having 6 and 3 learning outcomes in accordance with national mathematics curriculum respectively. Further, mathematics textbook of grade 8 addressed three students' proficiencies in mathematics i.e. understanding of mathematical concepts (CU), knowledge of mathematical procedures (PK), and solving mathematical problems (PS). Content of textbook with respect to proficiencies were found to be $30 \%, 40 \%$, and $30 \%$ for CU, PK, and PS respectively. 
Table 1

Table of Specification

\begin{tabular}{|c|c|c|c|c|c|}
\hline $\begin{array}{l}\text { Content } \\
\text { Strand }\end{array}$ & $\begin{array}{l}\text { Learning } \\
\text { Outcomes }\end{array}$ & $\begin{array}{c}\text { Items } \\
\mathrm{CU}\end{array}$ & $\begin{array}{c}\text { Items } \\
\text { PK }\end{array}$ & $\begin{array}{l}\text { Items } \\
\text { PS }\end{array}$ & Total \\
\hline \multirow{6}{*}{ 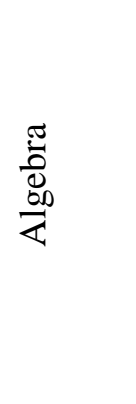 } & algebraic expressions & 1 & 3 & - & 4 \\
\hline & Solve equations & 1 & 1 & - & 2 \\
\hline & $\begin{array}{l}\text { Derivation, and } \\
\text { application of formulae }\end{array}$ & 2 & 1 & - & 3 \\
\hline & Factorization & 1 & 2 & - & 3 \\
\hline & $\begin{array}{l}\text { Solution of linear } \\
\text { equations }\end{array}$ & 1 & 1 & & 2 \\
\hline & $\begin{array}{l}\text { Problem solving } \\
\text { exercises }\end{array}$ & - & 1 & 6 & 7 \\
\hline \multirow{3}{*}{ 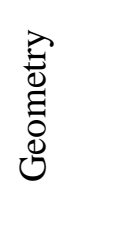 } & Pythagoras' theorem & 4 & - & 2 & 6 \\
\hline & $\begin{array}{l}\text { Sphere and cone (Area } \\
\text { and volume) }\end{array}$ & - & 1 & - & 1 \\
\hline & Area of rectangles & - & 3 & 1 & 4 \\
\hline Total & & 10 & 13 & 9 & 32 \\
\hline
\end{tabular}

Table 1 shows that there were total 32 test items $(10,13$, and 9 items for CU, PK, and PS). On the basis of Point-Biserial and items difficulty level researchers selected initially 52 items out of 280 items developed by NEAS. These were 35 items from Algebra and 17 items from Geometry. Secondly, subject matter experts of mathematics gave their opinions on 52 items about proficiencies addressed in mathematics textbook. Items i.e. 49 out of the 52 were selected on majority decision. Lastly, researchers finalized 32 items out of remaining 49 items based on Point-Biserial Correlation and difficulty index for good items.

\section{Teaching Module of Mathematics}

Mathematics at $8^{\text {th }}$ grade is compulsory subject. It is being taught using traditional teaching method employed by a solo teacher. Alternative to that co-teaching approach has many characteristics such as development of mutual trust and respect among co-teachers, develop interest of students in mathematics due to versatile styles of teaching Mathematics teachers in 
Pakistan are still using traditional method of teaching instead co-teaching, having many advantages. In Pakistan, Directorate of Staff Development (DSD) Lahore and United Nations Educational, Scientific, and Cultural Organization (UNESCO) had developed some modules of mathematics teaching for grade 8 . Those modules were developed for single teachers' teaching. There are some gaps in those modules DSD developed modules for arithmetic and geometry only. They did not use collaborative teaching settings to teach mathematics instead employed lecture and drill methods. For the same grade UNESCO developed module which covered both algebra and geometry, it addressed only few areas of both content strands. Those module used inductive and drill method to teach mathematics at grade 8. No co-teaching module has developed yet in Pakistan for teaching of $8^{\text {th }}$ grade mathematics. Lesson plans were developed in this study module. It has covered only algebra and geometry. Three co-teaching settings were employed in the module such as one-teach one-assist, team and parallel teaching. Further, with these collaborative settings some methods for example inductive, activity based, and problem solving methods and techniques like verbal question answers, tests, worksheets were used. Selection of a particular strategy by the co-teacher was based on the nature of the mathematical concept. The module was organized as algebra at first and second geometry as per order of curriculum and textbook of grade 8 mathematics.

\section{Research Ethics}

List of research ethics followed in this study were: permission was taken from the NEAS to use items from pool of items, punishment was avoided and students were treated with care, polite and in respectful way, volunteer participation of teachers in the experiment was done, secrecy of the data was ensured and kept confidential, anonymity of the respondents were ensured (Cohen, Manion \& Morrison, 2007) results were not deceptive, permission was taken from the school headmaster to conduct the study.

\section{Control of Variables}

The detail about the control of confounding variables was as follows: Co-equal teachers with respect o qualification and teaching experience were selected for conducting that experiment. They all were M.Sc. Mathematics and B.Ed. Pre-test and treatment interaction was measured 
by Factorial ANOVA, and was controlled using Solomon Four-Group research designs. Long duration experiment was conducted to control the effect of pre-testing. Random selection and assignment also helped to control this variable. With the same argument (i.e. long duration of experiment) novelty effect was controlled, validity and reliability of test items were ensure by NEAS Pakistan. Students' attendance was marked on daily basis and the scores of students were dropped for final data analysis whose attendance was less than $75 \%$.

\section{Results}

Before applying parametric statics such as independent sample t-test there is need to check the assumption of normality of the data. In order to check the normality of the data, the Shapiro-Wilk test of normality was applied. This test is useful with more than 50 cases. In this study data of 98 subjects were analyzed. The details are shown in Table 2.

Table 2

Normality of the Data of Control and Experimental Groups

\begin{tabular}{cccc}
\hline Group & Shapiro-Wilk & $d f$ & Sig. \\
& & & \\
\hline C & .97 & 53 & .22 \\
Ex. & .96 & 45 & .12 \\
\hline
\end{tabular}

Table 2 shows that $\mathrm{p}$ values $(0.22$ for control group and 0.12 for experimental group) are greater than the 0.05 . The null hypotheses for the Shapiro-Wilk test were accepted. It means that data of both groups is significantly normal. The normality of data was also checked by plotting Q-Q-plot.

Figures 4 and 5 showed data on straight line. So, data collected through test were distributed normally. Data of both experimental and control groups were shown normal. 


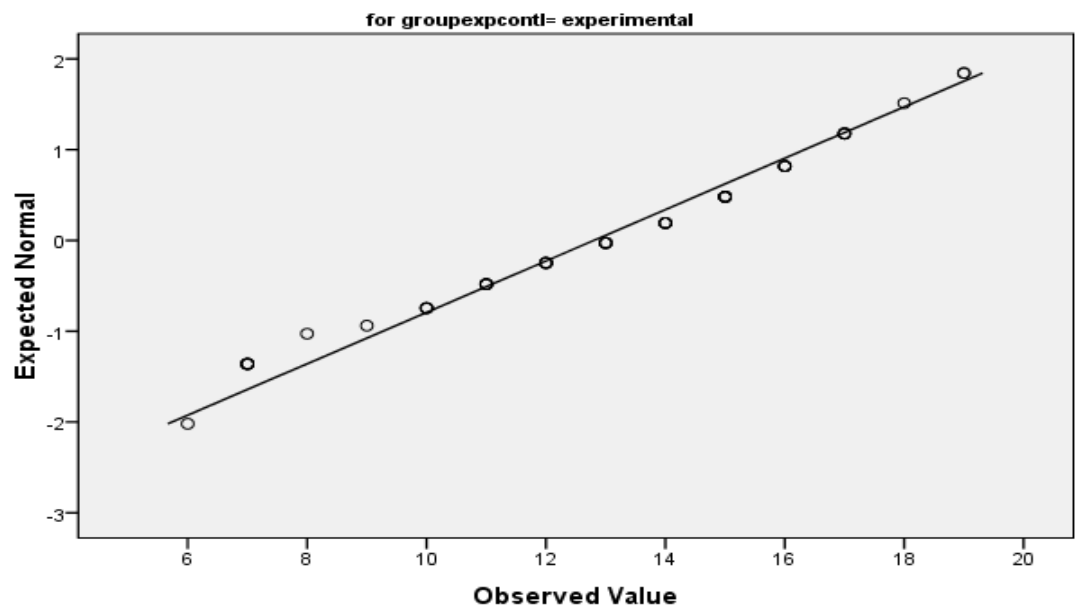

Figure 4: Q-Q plot for experimental group

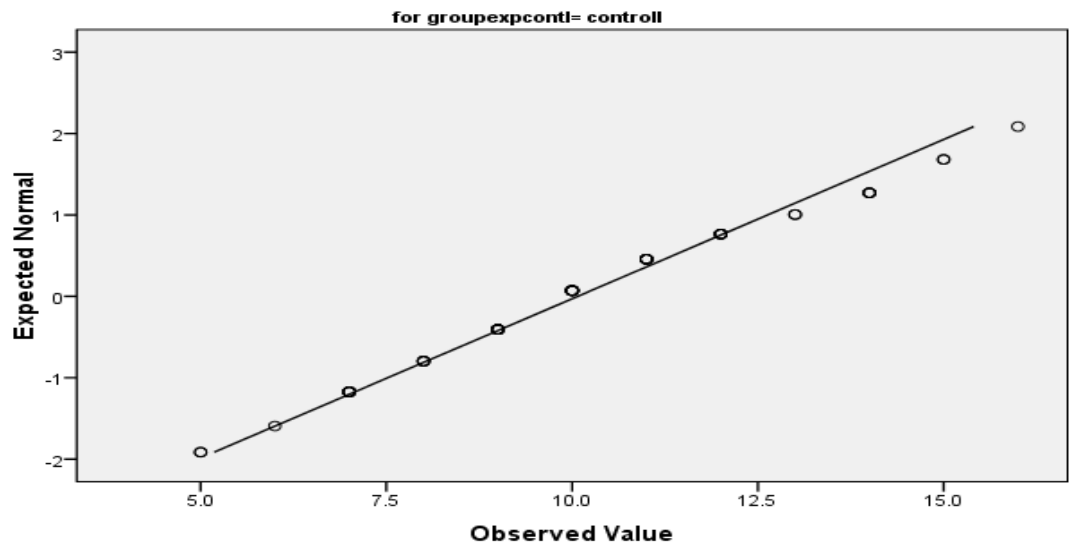

Figure 5: Q-Q plot for control group 


\section{Students' Scores in Algebra and Geometry with Mathematical Proficiencies}

Null Hypotheses were tested by using independent sample t-test. There were two groups in the study i.e. experimental and control. The means scores were shown in table 3 .

Table 3

Mean Scores of Experimental, Control with and without Pre-test

\begin{tabular}{llll}
\hline Groups & With Pre-test & without Pre-test & Total \\
\hline Ex & 12.29 & 13.38 & 12.80 \\
C & 10.38 & 9.83 & 10.08 \\
Total & 11.33 & 11.32 & \\
\hline
\end{tabular}

Note: $\mathrm{Ex}=$ Experimental and $\mathrm{C}=\mathrm{Control}$

Table 4

Comparison between students' achievement scores of experimental and control groups on proficiencies i.e. understanding of mathematical concepts, knowledge of mathematical procedures and solving mathematical problems on items from Algebra

\begin{tabular}{|c|c|c|c|c|c|c|c|c|}
\hline $\begin{array}{l}\text { Conten } \\
\mathrm{t} \\
\text { Strand }\end{array}$ & $\begin{array}{l}\text { Proficienc } \\
\mathrm{y}\end{array}$ & $\begin{array}{l}\mathrm{Gr} \\
\mathrm{ou} \\
\mathrm{p}\end{array}$ & $\mathrm{N}$ & $\bar{x}$ & $\begin{array}{l}\text { Std. } \\
\text { Deviation }\end{array}$ & $d f$ & $t$ & Sig. \\
\hline \multirow{6}{*}{$\begin{array}{l}\frac{\pi}{0} \\
0 \\
\frac{0}{2} \\
\frac{0}{2}\end{array}$} & \multirow[t]{2}{*}{$\mathrm{CU}$} & $\mathrm{C}$ & 53 & $\begin{array}{l}2.1 \\
6\end{array}$ & 1.28 & 9 & \multirow{2}{*}{-3.54} & .00 \\
\hline & & Ex & 45 & 3.1 & 1.27 & 6 & & 1 \\
\hline & \multirow[t]{2}{*}{ PK } & $\mathrm{C}$ & 53 & $\begin{array}{l}2.7 \\
3\end{array}$ & 1.19 & 9 & \multirow{2}{*}{-3.59} & 00 \\
\hline & & Ex & 45 & 3.8 & 1.61 & 6 & & 1 \\
\hline & \multirow[t]{2}{*}{ PS } & $\mathrm{C}$ & 53 & 1.7 & 0.91 & $\begin{array}{l}9 \\
6\end{array}$ & \multirow[t]{2}{*}{-.28} & \multirow[t]{2}{*}{.78} \\
\hline & & Ex & 45 & 1.8 & 1.09 & & & \\
\hline
\end{tabular}

Note: $\mathrm{CU}=$ understanding of mathematical concepts, $\mathrm{PK}=$ knowledge of mathematical procedures and $\mathrm{PS}=$ solving mathematical problems, Ex=Experimental, $\mathrm{C}=$ Control

$\mathrm{p}=.05(\mathrm{df}=96)$ 
No significant difference was found in collaborative and single teacher teaching groups students' mean scores on the problem solving items related to algebra in the achievement test with significant value $\mathrm{p}=$ $0.78>0.05$. But significant difference was found in students' mean scores taught through CT and traditional single teacher teaching on conceptual and procedural knowledge algebra items with significant values 0.001 and $0.001<0.05$. The mean achievement scores of students indicated that experimental group students performed better on test items related to conceptual and procedural knowledge items of algebra than control group students. Details are shown on figure 6.

Table 5

Comparison between students' (experimental and control groups) achievement scores on mathematical understanding, procedures and solving mathematical problems on items from Geometry

\begin{tabular}{|c|c|c|c|c|c|c|c|c|}
\hline $\begin{array}{l}\text { Content } \\
\text { Strand }\end{array}$ & Proficiency & Group & $\mathrm{N}$ & $\bar{x}$ & $\begin{array}{c}\text { Std. } \\
\text { Deviation }\end{array}$ & $d f$ & $t$ & Sig. \\
\hline \multirow{6}{*}{$\begin{array}{l}\overleftrightarrow{E} \\
\stackrel{0}{0} \\
0 \\
0\end{array}$} & \multirow{3}{*}{$\mathrm{CU}$} & $\mathrm{C}$ & 53 & 1.52 & 0.75 & \multirow{3}{*}{96} & \multirow{3}{*}{-1.27} & \multirow{3}{*}{0.21} \\
\hline & & Ex & 45 & 1.71 & 0.66 & & & \\
\hline & & $\mathrm{C}$ & 53 & 1.37 & 0.97 & & & \\
\hline & PK & Ex & 45 & 1.60 & 1.03 & 96 & -1.10 & 0.27 \\
\hline & \multirow[t]{2}{*}{ PS } & $\mathrm{C}$ & 53 & 0.57 & 0.75 & \multirow[t]{2}{*}{96} & \multirow[t]{2}{*}{-2.06} & \multirow[t]{2}{*}{0.04} \\
\hline & & Ex & 45 & 0.9 & 0.80 & & & \\
\hline
\end{tabular}

Note: $\mathrm{CU}=$ understanding of mathematical concepts, $\mathrm{PK}=$ knowledge of mathematical procedures and $\mathrm{PS}=$ solving mathematical problems, Ex=Experimental, $\mathrm{C}=\mathrm{Control}$

$\mathrm{p}=.05(\mathrm{df}=96)$

No significant difference was found in collaborative and single teacher teaching groups students' mean scores on the conceptual understanding, 
and procedural knowledge items related to geometry in the achievement test. The significant values 0.21 and 0.27 were greater than 0.05 respectively. But significant difference was found in students' mean scores taught through CT and traditional single teacher teaching on problem solving geometry items as the value of $\mathrm{t}_{96}=-2.06, \mathrm{p}=0.04<0.05$. Figure 6 were showing the details.

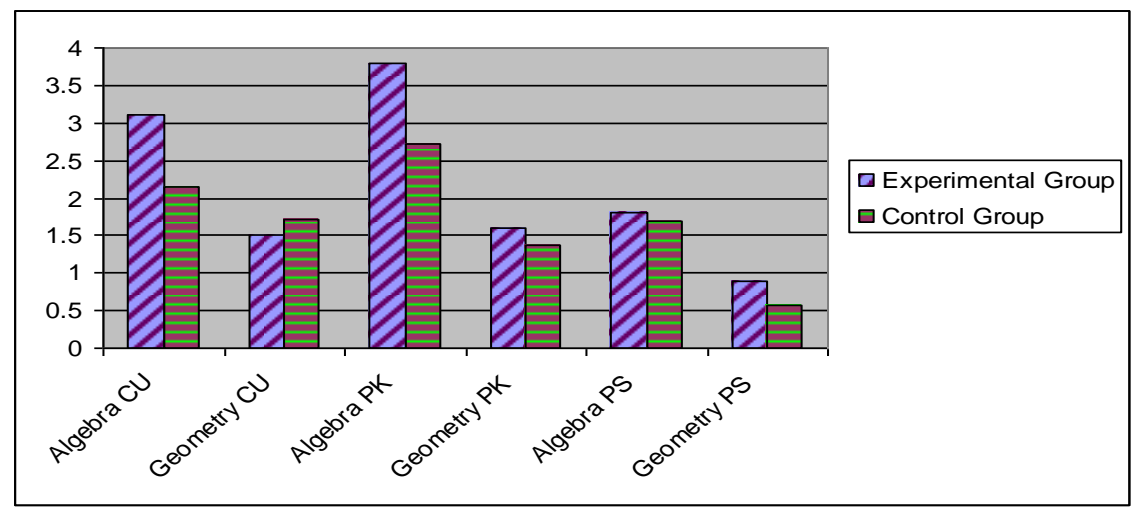

Figure 6: Students Mean scores on mathematical proficiencies in Algebra and Geometry

\section{Discussion}

Co-teaching is being used as an alternative approach to teaching of mathematics with traditional teaching (single teacher teaching predominantly by using deductive method of teaching). The studies at international level in developed countries showed its effectiveness to enhance students score (Mcduffe et al., 2007). In this study, it was found that co-teaching was effective in the understanding of mathematical concepts and knowledge of mathematical procedures in algebra but not in problem solving proficiency. It showed improvement of students' scores in problem solving proficiency on items of Geometry but not on items of conceptual understanding and knowledge of mathematical procedures. These results may be due to teaching of mathematics in English language as directed by National Educational Policy (2009). Earlier, Mathematics books and teaching of Mathematics were in Urdu, National Language of 
Pakistan, in public schools of Punjab province. Additionally, the test items were also developed in English. Due to low command on English students studying at $8^{\text {th }}$ grade in public schools got low scores in problem solving items of algebra. As this new approach to teaching of mathematics was exposed first time in schools, they might have adjustment problems. The size of the groups was also a critical factor for these results. The result of the study opens new ways to adapt new approach of co-teaching in Pakistan.

\section{Conclusions}

The conclusions were based by the findings of this study. Effectiveness of co-teaching was explored in this study in Algebra and Geometry. It was concluded that co-teaching a better alternative to single teachers teaching (with deductive method of teaching) in Pakistan. Moreover, it was concluded that for algebra co-teaching was better alternative to single teachers' teaching to improve students' scores in understanding of mathematical concepts and knowledge of mathematical procedures but not for students' problem solving ability. In contrast, it was also concluded that for geometry co-teaching was an effective teaching approach as compared to single teachers' teaching to improve students' scores in problem solving but not for improving students' scores in understanding of mathematical concepts and knowledge of mathematical procedures.

\section{Suggestions and Recommendations}

Based on the results of this research it was suggested that public schools may adapt co-teaching, a new approach to teach mathematics at grade 8 . The study was based on true experimental design with controlling many confounding variables, so it may be replicated. It was recommended that a topic on co-teaching should be included in courses preparing teachers of Mathematics. A teaching module may be developed covering all content strands of mathematics. It may be extended to different grade levels and by using different collaborative settings for mathematics 
teaching. Further research may examine the effectiveness of co-teaching in different mathematical content stands and on different grade levels. Qualitative research may also be conducted to investigate the perceptions about the effectiveness of co-teaching. 


\section{References}

Ahmad, F. (2014). Effect of cooperative learning on students' achievement at elementary level. The International Journal of Learning, 17(3), 127-142.

Akhtar, K., Perveen, Q., Kiran,S., Rashid,M., \& Satti, A. K. (2012). A study of student's attitudes towards cooperative learning. International Journal of Humanities and Social Science. 2(11), 141147 Retrieved from http://www.ijhssnet.com/journals/Vol_2_No_11_June_2012/15.pdf

Almon, S. \& Feng, J. (2012, November). Co-teaching vs. solo-teaching: effect on fourth graders' math achievement. Paper presented at MidSouth Educational Research Association Annual Conference, Lexington, Kentucky, USA.

Best, W. J. \& Kahn, V. J. (2008). Research in education. New Delhi, India: Pearson Education Friend, M. \& Cook, L. (2000). Interaction: collaboration skills for school professionals (3rd ed.). New York, USA: Addison Wesley Longman, Inc.

Cohen, L., Manion, L., \& Morrison, K. (2007). Research methods in education (6th ed.). NY, USA: Routledge.

Creswell, W. J. (2002). Research design: qualitative, quantitative, and mix-methods approaches ( $4^{\text {th }}$ ed.). New York, USA: Pearson Education, Inc.

Fraenkel, R. J. \& Wallen, E. N. (2006). How to design and evaluate research in education. NY, USA: Mc- Graw Hill.

Goddard, L.Y., Goddard, D. R., \& Moran, T.M. (2007). A theoretical and empirical investigation of teachers collaboration for school improvement and students achievement in public elementary schools. Teacher college record, 109(4), 877-896. 
Iqbal, M. (2004). Effect of cooperative learning on academic achievement of secondary school students in mathematics (PhD Dissertation). Retrieved from http://eprints.hec.gov.pk/388/1/239.html.htm

Jang, S. (2006). Research on the effects of team teaching upon two secondary schoolteachers. Educational Research, 48(2), 177-194.

Khan, S. A. (2008). An experimental study to evaluate the effectiveness of cooperative learning versus traditional learning method $(\mathrm{PhD}$ Dissertation). Retrieved from http://eprints.hec.gov.pk/6517/

Mcduffe, A. K., Scruggs, E. T., \& Mastropieri, A.M. (2007). Co-teaching in inclusive classroom: results of qualitative researches from US, Canada, and Australia. International Perspectives Advances in Learning and Behavioral Disabilities, 20, 311-338.

National Educational Policy (2009), Ministry of Education Islamabad, Pakistan.

Parker, A.K. (2010). The impacts of co-teaching on the general education student (Ed.D). Retrieved from

http://etd.fcla.edu/CF/CFE0003005/Parker_Alicia_K_201005_EDD.pdf

Parrott, P. (n. d.). Instructional Strategies for co-teaching \& inclusion. An instructor of M.Ed. class in the University of Richmond.

Robinson, B., \& Schaible, R. M. (1995). Collaborative teaching: reaping the benefits. College-Teaching, 43, 57-59.

Russell, D. (2006). Overcoming math anxiety. Retrieved from http://math.about.com/od/reference/a/anxiety.htm

Sperling, M. (1994). Speaking of writing: when teacher and student collaborate. In Reagan, S. B., Fox, T., \& Bleichl, D. (Eds.). Writing with: new directions in collaborative teaching, learning, and research, 213 - 227. Albany, NY: State University of New York Press.

Wilson, V. A., \& Martin, K. M. (1998). Practicing what we preach: team teaching at the college level. Paper presented at the Annual Meeting of 
the Association of Teacher Educators (ERIC document reproduction service no. ED 417172).

Witcher, M. \& Feng, J. (2010, November). Co-teaching vs. solo teaching: comparative effects on fifth graders' math achievement. Paper presented at the Mid-South Educational Research Association Annual Conference, Alabama.

\section{Citation of this Article:}

Iqbal, M. Z., \& Shams, J. A. (2018). Co-teaching effectiveness: Students' achievement in mathematical proficiencies and content strands. Pakistan Journal of Education, 35 (3), 39-58. 